\title{
Introducing a new service of a midwife-led telephone follow-up clinic for 3a \& 3b Obstetric Anal Sphincter Injury: retrospective service evaluation and patients' satisfaction survey
}

\author{
SAMI SHAWER ${ }^{1}$, SAMREEN INNAYAT ${ }^{1}$, HALEY HUTCHINSON ${ }^{2}$, PAUL BALLARD ${ }^{2}$ \\ AND AETHELE KHUNDA ${ }^{2}$ \\ ${ }^{\prime}$ North Tees and Hartlepool NHS Foundation Trust, \\ ${ }^{2}$ South Tees NHS Foundation Trust \\ Diakonissenkrankenhaus Flensburg, Flensburg, Germany
}

\begin{abstract}
Background Most patients with 3a and 3b perineal tears will be asymptomatic. The need for all patients to attend a hospital appointment can be questioned. We set up a midwife-led telephone review clinic for such injuries. We aim to evaluate this service by auditing it and also by analysing patients' satisfaction through a patient satisfaction survey. Methods We performed retrospective analysis of the patients' notes over 18 months. We evaluated this service by auditing its adherence to specified standards within the local guidelines and by performing a patients' satisfaction survey of the new service via anonymised postal Friends and Family test. Results We looked at 66 sets of notes, of which 48 had datasets with complete clinical/symptomatic data. 14/21 3a and 17/27 3b OASI were asymptomatic and discharged. Only 3 patients with 3a tear and 6 with $3 \mathrm{~b}$ tear were referred to the consultant-led clinic. From 89 patients who had a midwife-led telephone clinic, 21 responded to the postal survey (23.6\%). Two had not received their telephone appointment. 17/19 (89.4\%) responded very good or good to the question "how well do you think your questions and concerns were addressed'. 16/19 (84.2\%) responded extremely likely or likely to the question 'how likely are you to recommend this service to friends and family'. Conclusions A midwife-led telephone follow-up clinic for patients who sustained $3 \mathrm{a}$ and $3 \mathrm{~b}$ tears seems to be an acceptable service for these patients with high satisfaction rate. We believe that this service has the potential to save time and resources for both patients and healthcare providers.
\end{abstract}

Keywords: Midwife-led; Perineal clinic; OASI; OASIS; Telephone clinic

\section{INTRODUCTION}

The reported incidence of Obstetric Anal Sphincter Injury (OASI) appears to have tripled between 2000 and 2012 from $1.8 \%$ to $5.9 \%$, and much of this is likely to be due to better recognition ${ }^{1}$. The overall incidence is $6.1 \%$ in primiparas and $1.7 \%$ in multiparas ${ }^{2}$.

The Royal College of Obstetricians and Gynaecologists (RCOG) guideline has recommended a system for grading the perineal tears ${ }^{3}$. Approximately $80 \%$ of injuries are $3 \mathrm{a}$ and $3 \mathrm{~b}$ tears, and the rest are $3 \mathrm{c}$ and 4 th degree tears ${ }^{4,5}$.

The data on the presence of symptoms varies enormously. The presence of symptoms in those with a $3 \mathrm{a}$ and $3 \mathrm{~b}$ injuries can be as high as $31.7 \%$ at 3 months postnatal ${ }^{4}$ and as little as $7 \%$ at 6 months postnatal ${ }^{5}$ and by far the most common symptom being faecal urgency.

The RCOG guideline recommended that all patients with OASI should have follow-up appointment by clinicians with a special interest in OASIS. However, it did not comment on different methods of follow-up or care for different grades of OASI. The need for routine hospital review of all women with $3 \mathrm{a}$ injuries has been called into question, and given that only $8.6 \%$ of $3 \mathrm{~b}$ injuries are symptomatic at 6 months ${ }^{5}$, hospital follow-up may not be required in this subgroup either. We introduce a new service of a midwife-led telephone follow-up clinic for all patients who sustained $3 \mathrm{a}$ and $3 \mathrm{~b}$ tears. We aim to evaluate this service by auditing its adherence to specified standards within the local guidelines and also by analysing patients' satisfaction with this service through an anonymous patient satisfaction survey.

\section{MATERIALS AND METHODS}

The Clinic Process

We introduced the midwife-led telephone follow-up clinic for patients suffering from 3a and 3b OASI in September 2013. This clinic is led by three midwives (band 6/7), who are already trained to discuss Obstetric trauma and morbidity for the 'Talking about Birth' (TAB) clinic. They use a set proforma to assess and counsel patients over the telephone.

Prior to discharge, all patients who sustained a third or fourth degree tear were provided with a patient information sheet on OASI and pelvic floor muscle exercises.

After discharge, all the notes were reviewed by a consultant urogynaecologist with an interest in pelvic floor trauma. Patients with $3 \mathrm{a}$ and $3 \mathrm{~b}$ tears were scheduled to have a midwife-led telephone appointment at 12 weeks postpartum unless they didn't speak English, or if there were any specific reasons warranting their review by a consultant.

An appointment time and date were sent out with the appropriate explanation to be near the telephone and allow minimum of 10 minutes either side of the appointment time. If the midwife could not speak to the patient on the telephone despite trying twice over a 10 minutes period, the patient was sent a further appointment. If on this occasion there was no reply, the patient was classified as having defaulted the appointment (DNA) and therefore discharged back to primary care (Fig. 1).

The telephone discussion included faecal symptoms, pain, intercourse, debrief of the trauma and options for future deliveries. Patients were informed that if they had no symptoms, the chance of developing new symptoms after a further vaginal delivery was low and further discussion regarding mode of delivery could take place in the future pregnancy when other factors could be considered, before the final decision was made. All patients were given the option of attending the consultant clinic if they wished.

All patients who had ongoing faecal symptoms at first review were referred to the consultant clinic. Those with anal discomfort but no faecal symptoms received further telephone reviews from the midwife until resolution and discharge or referral to the consultant. The degree of bothersomeness on a 0-10 analogue scale was recorded for faecal incontinence, faecal urgency, flatal incontinence and perineal pain for each patient. 
Figure 1. Process of follow-up for patients with OASI
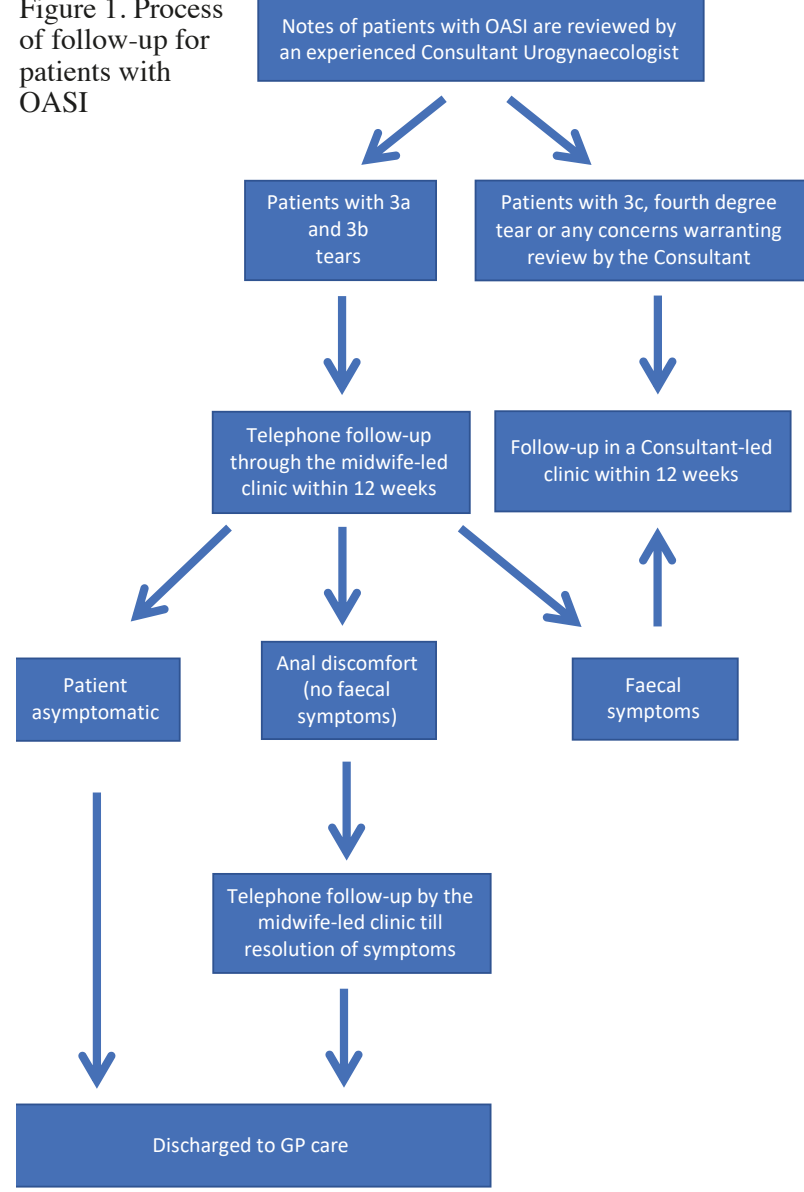

The Database:

An OASI database had been kept by the trust just prior to the set-up of the midwife-led telephone clinic, to enable contemporaneous audit. This database continued to be used during the period of the study. As part of this service evaluation, we evaluated the outcome data from the database for the index period: $1^{\text {st } J a n u a r y ~} 2014-30^{\text {th June }} 2015$.

\section{The Audit:}

The primary standard in this audit of the midwife-led clinic was that all women who had faecal symptoms should be offered a consultant clinic appointment - standard $100 \%$. An additional standard was that $90 \%$ of women should have documentation that the mode of delivery was discussed. We felt that $100 \%$ adherence would not be proper for this latter standard as there might be circumstances when it would be inappropriate to discuss this at first consultation.

We performed retrospective data collection for 66 patients (random sample of notes) who sustained OASI in the period from $1^{\text {st }}$ of January 2014 to $30^{\text {th }}$ of June 2015, who had an appointment with the midwife-led telephone clinic, to establish whether these standards had been met. The patients were identified by using our clinic management IT system Camis.

Postal satisfaction survey:

All the patients who had scheduled follow-up by the midwife-led clinic received a trust produced anonymised postal patient satisfaction questionnaire six months following delivery, which included the 'friends and family' test (www. england.nhs.uk/ourwork/pe/fft/) with a stamped addressed envelope for its return.

Audit department permission was granted for the notes review and the postal questionnaire. Ethics approval was not required as all data was anonymised for the audit.

\section{RESULTS}

\section{Outcome data from the database for index period}

During the 18 month period under review, there were 6708 deliveries out of which 5339 were vaginal. 147 women sustained OASI which constituted $2.7 \%$ of vaginal deliveries. 54 injuries were $3 \mathrm{a}(36.7 \%), 59$ were $3 \mathrm{~b}(40.1 \%)$, 19 were $3 c(12.9 \%), 15$ were $4^{\text {th }}$ degree OASI $(10.2 \%)$.

During that period, 89 of 113 3a and 3b OASI patients were scheduled as new patients for the telephone clinic and the remaining 24 were scheduled for the consultant clinic for various reasons as above. Of the 89 listed for the telephone clinic, 23 (26.1\%) 'did not attend' (DNA) and an additional 15 patients were scheduled as follow up within the index period, of whom 1 did not attend (6\% DNA rate).

Table 1 and Table 2 describe the patients' demographics and symptoms at the first review respectively.

\section{Audit of midwifery clinic adherence to guidelines}

We looked at 66 sets of notes, of which 48 had datasets with complete clinical/symptomatic data. In the remaining 18 sets of notes, clinical data were missing for a variety of reasons (see below).

$3 a$ Injuries:There were 21 patients who had sustained a $3 \mathrm{a}$ OASI, of whom 14 (66.6\%) were completely asymptomatic at telephone follow-up and discharged. Seven patients were symptomatic at telephone follow-up, 3 of whom were

Table 1. Graded Obstetric Anal Sphincter Injury for the period 01.01.14 - 30.06.15. Total Unit data collected from local OASI database

\begin{tabular}{|c|c|c|c|c|}
\hline & $3 a(n=54)$ & $3 b(n=59)$ & $3 c(n=19)$ & $4(n=15)$ \\
\hline $\begin{array}{l}\text { Proportion of vaginal deliveries - } \\
5339\end{array}$ & $1.01 \%$ & $1.11 \%$ & $0.36 \%$ & $0.28 \%$ \\
\hline Proportion of all OASI & $36.7 \%$ & $40.1 \%$ & $12.9 \%$ & $10.2 \%$ \\
\hline Age (years) - mean (range) & $\begin{array}{c}27.6 \\
(19-37) \\
\end{array}$ & $\begin{array}{c}28.5 \\
(20-42) \\
\end{array}$ & $\begin{array}{c}29 \\
(17-35) \\
\end{array}$ & $\begin{array}{c}28.7 \\
(20-33) \\
\end{array}$ \\
\hline Parity & $\begin{array}{l}0=39 \\
1=14 \\
2=1\end{array}$ & $\begin{array}{c}0=49 \\
1=9 \\
2=1\end{array}$ & $\begin{aligned} 0 & =16 \\
1 & =3 \\
2 & =0\end{aligned}$ & $\begin{array}{l}0=9 \\
1=4 \\
2=2\end{array}$ \\
\hline $\begin{array}{l}\text { Previous } 3^{\text {rd }} \text { degree } \\
\text { Tear }\end{array}$ & 4 & 0 & 1 & 0 \\
\hline Mode Of Delivery & $\begin{array}{l}\text { Normal }=40 \\
\text { Forceps }=14 \\
\text { Ventouse }=0\end{array}$ & $\begin{array}{l}\text { Normal }=23 \\
\text { Forceps }=30 \\
\text { Ventouse }=6\end{array}$ & $\begin{array}{c}\text { Normal }=14 \\
\text { Forceps }=4 \\
\text { Ventouse }=1 \\
\end{array}$ & $\begin{array}{c}\text { Normal }=10 \\
\text { Forceps }=4 \\
\text { Ventouse+forceps }=1\end{array}$ \\
\hline Birth Weight (g) - mean (range) & $\begin{array}{c}3654 \\
(2260-4600) \\
\end{array}$ & $\begin{array}{c}3634 \\
(2350-4595) \\
\end{array}$ & $\begin{array}{c}3516 \\
(2910-4255) \\
\end{array}$ & $\begin{array}{c}3690 \\
(2685-4375) \\
\end{array}$ \\
\hline Episiotomy rate & $16(29.6 \%)$ & $18(30.5 \%)$ & $6(31.6 \%)$ & $6(40 \%)$ \\
\hline
\end{tabular}


Table 2. Symptoms at First Review for all patients (Total unit data collected from local OASI database) during index period. Symptoms bothersomeness graded $0-10,0=$ no bother, $10=$ maximum bother.

\begin{tabular}{|c|c|c|c|c|}
\hline Grade of OASI & $3 \mathrm{a}$ & $3 b$ & $3 \mathrm{c}$ & 4 \\
\hline No. patients in group & 54 & 59 & 19 & 15 \\
\hline No. patients with symptom data & 35 & 41 & 12 & 13 \\
\hline No. patients with faecal incontinence & $2(5.7 \%)$ & $3(7.3 \%)$ & $1(8.3 \%)$ & $1(7.7 \%)$ \\
\hline $\begin{array}{r}\text { Faecal incontinence bother - Mode } \\
\text { Median } \\
\text { Interquartile range }\end{array}$ & $\begin{array}{c}2 \\
2 \\
2,2 \\
\end{array}$ & $\begin{array}{c}4 \\
4 \\
4,1 \\
\end{array}$ & $\begin{array}{l}7 \\
7\end{array}$ & $\begin{array}{l}3 \\
3\end{array}$ \\
\hline No. patients with faecal urge & $4(11.4 \%)$ & $13(31.7 \%)$ & $4(33 \%)$ & $3(23 \%)$ \\
\hline $\begin{array}{r}\text { Faecal urge bother - Mode } \\
\text { Median } \\
\text { Interquartile range }\end{array}$ & $\begin{array}{c}2 \\
4 \\
2,6 \\
\end{array}$ & $\begin{array}{c}3,9 \\
6 \\
3,9 \\
\end{array}$ & $\begin{array}{c}4 \\
5 \\
4,6 \\
\end{array}$ & $\begin{array}{c}5 \\
5 \\
4,5 \\
\end{array}$ \\
\hline No. patients with flatal incontinence & $1(2.9 \%)$ & $11(28.6 \%)$ & $3(25 \%)$ & $3(23.1 \%)$ \\
\hline $\begin{array}{r}\text { Flatal incontinence bother }- \text { Mode } \\
\text { Median } \\
\text { Interquartile range }\end{array}$ & $\begin{array}{l}2 \\
2\end{array}$ & $\begin{array}{c}7 \\
7 \\
3,7 \\
\end{array}$ & $\begin{array}{c}1 \\
1 \\
1,6 \\
\end{array}$ & $\begin{array}{c}2 \\
2,5 \\
\end{array}$ \\
\hline No. patients with pain & $5(14.3 \%)$ & $10(24.4 \%)$ & $3(25 \%)$ & $1(7.7 \%)$ \\
\hline
\end{tabular}

referred on to the consultant clinic. Of the 4 patients ultimately discharged by the midwife clinic, 3 had discomfort around the anal area, which on subsequent telephone review had resolved, the fourth in addition to discomfort also described flatal incontinence but declined further review. Of the 3 patients referred to the consultant clinic, 2 had faecal urgency and the other had pain in the perineum.

The documentation suggests that 19 of the 21 patients had a discussion about the next delivery.

$3 b$ Injuries: there were 27 patients who sustained a $3 \mathrm{~b}$ OASI, of whom 17 (62.9\%) were completely asymptomatic at telephone review and discharged. Of the 10 patients who had symptoms, 6 were referred on to the consultant clinic. Of the 4 patients discharged by the midwife, 1 had faecal urgency but declined further follow-up, 1 had pain and rectal bleeding and was referred on to the GP, 1 had rectal bleeding and declined further follow-up and the last one had faecal urgency and rectal bleeding and her outcome was uncertain (inadequate documentation).

Of those 6 patients referred to the consultant clinic, 2 had faecal urgency ( 1 of whom did not attend the consultant appointment), 1 had flatal incontinence (she did not attend the

Table 3: Postal Satisfaction questionnaire results (answers are from a 7 point scale except for question 5 , which is from a 5 point scale)

\begin{tabular}{|c|c|c|}
\hline Question & Response & $\begin{array}{l}\text { Midwife } \\
\text { telephone } \\
\text { clinic } \mathrm{N}=19\end{array}$ \\
\hline \multirow{3}{*}{$\begin{array}{l}\text { 1. How well do you } \\
\text { think your questions } \\
\text { and concerns were } \\
\text { addressed? }\end{array}$} & Very good / Good & $17(89.4 \%)$ \\
\hline & Satisfactory & $2(10.5 \%)$ \\
\hline & \begin{tabular}{|l|} 
Neither good nor bad \\
Poor, Bad or Very bad
\end{tabular} & $0(0 \%)$ \\
\hline \multirow{3}{*}{$\begin{array}{l}\text { 2. How good was the } \\
\text { explanation detailing } \\
\text { the injury you had? }\end{array}$} & Very good / Good & $16(84.2 \%)$ \\
\hline & \begin{tabular}{|l|} 
Satisfactory \\
\end{tabular} & $3(15.8 \%)$ \\
\hline & \begin{tabular}{|l|} 
Neither good nor bad \\
Poor, Bad or Very bad
\end{tabular} & $0(0 \%)$ \\
\hline \multirow{3}{*}{$\begin{array}{l}\text { 3. How well do you } \\
\text { feel your options in } \\
\text { a future pregnancy } \\
\text { were discussed }\end{array}$} & Very good / Good & $12(63.2 \%)$ \\
\hline & \begin{tabular}{|l|} 
Satisfactory \\
\end{tabular} & $3(15.8 \%)$ \\
\hline & $\begin{array}{l}\text { Neither good nor bad } \\
\text { Poor, Bad or Very bad }\end{array}$ & $4(21.0 \%)$ \\
\hline \multirow{3}{*}{$\begin{array}{l}\text { 4. Overall rate the } \\
\text { service }\end{array}$} & Very good / Good & $12(63.2 \%)$ \\
\hline & \begin{tabular}{|l} 
Satisfactory \\
\end{tabular} & $5(26.3 \%)$ \\
\hline & $\begin{array}{l}\text { Neither good nor bad } \\
\text { Poor, Bad or Very bad }\end{array}$ & $2(10.6 \%)$ \\
\hline \multirow{2}{*}{$\begin{array}{l}\text { 5. How likely are } \\
\text { you to recommend } \\
\text { this service to } \\
\text { Friends and Family? } \\
\text { (5 point scale) }\end{array}$} & Extremely likely / Likely & $16(84.2 \%)$ \\
\hline & $\begin{array}{l}\text { Neither likely nor unlikely / } \\
\text { Unlikely / Extremely unlikely } \\
\text { (I don't know) }\end{array}$ & $3(15.8 \%)$ \\
\hline
\end{tabular}

consultant appointment), 2 patients had faecal incontinence, faecal urgency and flatal incontinence, and a one patient had a 'bulge in her perineum'.

The documentation suggests that 24 of the 27 patients had a discussion about the next delivery.

Therefore, in 1 of the 17 symptomatic patients with a $3 \mathrm{a}$ or $3 \mathrm{~b}$ OASI, there is uncertainty from notes review, as to whether they were offered a consultant review, giving a $94.2 \%$ adherence to the first standard. In addition, there was evidence of a discussion regarding mode of delivery in $89.6 \%$ notes.

Of the 18 sets of notes where there was incomplete data, 11 patients missed their telephone appointments on 2 occasions and were discharged. In 2 notes, the OASI pathway was missing. 2 patients declined follow-up. And in the remaining 3 patients, there was inadequate documentation by the midwife. Overall, when the OASI pathway document was present, there were $4(6.3 \%)$ notes out of the 64 where the documentation was inadequate to determine whether the patient should have been, or was offered a consultant review.

\section{Postal satisfaction survey of the midwife-led telephone OASI service}

Of the 89 patients scheduled for the midwife-led telephone follow-up, 21 responded to the postal survey $(23.6 \%)$. Two had not received their telephone appointment. The results of the remaining 19 appear in table 3.

As the response rate was low, the answers have been grouped into 3 groups: 1 . very good/good, 2. satisfactory or 3 . neither good nor bad/poor/bad/very bad.

Overall, patients' acceptance of the midwife-led telephone clinic seemed to be high with high satisfaction rates. $89.5 \%$ of the patients rated the service as very good, good or satisfactory. $84.2 \%$ of the patients answered that they are likely or extremely likely to recommend this service to friends and family.

\section{DISCUSSION}

The aim of this service evaluation was to determine whether the adherence to our standards was met, and to determine the acceptability of the service to our patients through the patients' satisfaction survey.

The audit of adherence to agreed standards revealed few points of practice that could be improved. There was 1 symptomatic patient in whom the documentation appeared to be inadequate to explain why this patient was not referred on to the consultant clinic. 3 further patients appeared to have no documentation. The reason for this is uncertain but could include failure to document or documentation in the incorrect place. The second standard reviewed; evidence of a discussion regarding mode of delivery fell just short of the standard 
set. The need for documentation has been re-emphasised, including reason for non-compliance with guidelines, and these will be re-audited at a later date.

Our data from the postal survey reveals that the patients were generally happy with the midwife-led telephone consultation with $84 \%$, likely or extremely likely to recommend this service to friends and family. The results suggest that appropriately trained midwives can provide the first follow-up consultation over the telephone following an OASI, referring on those patients with continuing symptoms for further assessment.

The published data regarding the management of OASI is mainly retrospective and is often conflicting. Therefore, counselling patients can be challenging. Understandably, much of the published literature infers a worse outcome and a greater frequency of symptoms following a $3 \mathrm{c}$ or 4 th degree OASI compared to less severe injuries.

Review at 3 months, in one large study, suggested that the frequency of symptoms in the $3 \mathrm{a}$ and $3 \mathrm{~b}$ OASI were similar to $3 \mathrm{c}$ and $4 \mathrm{th}^{4}$. However, there appears to be an increasing frequency of faecal symptoms with worsening grade of injury at six months review ${ }^{5}$. This may suggest that some of those with symptomatic 3a and 3b OASI become asymptomatic between 3 and 6 months. Several studies have suggested that by twelve months postnatal $60-80 \%$ of patients will be asymptomatic ${ }^{3}$. The emphasis in the updated version of the RCOG guideline is slightly more pragmatic suggesting, 'Women who have undergone anal sphincter repair should be reviewed at a convenient time (usually 6-12 weeks postpartum). Where possible, the review should be by a clinician with a special interest in OASIS'.

Experienced midwives are performing an increasing number of roles, previously performed by doctors. Although review by an experienced consultant with the appropriate expertise may be optimal, this is of little benefit to some if they struggle to get to the hospital and are therefore more inclined not to attend. Telephone consultations are used in many specialties such as dermatology, ENT, colorectal surgery ${ }^{6-8}$, and indeed in urogynaecology ${ }^{9}$. Following urogynaecological surgical procedures, the need for routine follow-up has been called into question, suggesting patients will re-present if they have complications ${ }^{10}$. However, follow-up after OASI, is for information giving, as much as it is about information gathering and some time is required to allow the new mother to adjust to the changes in her life, so a discussion downstream from delivery is appropriate, as well as immediately post-delivery.

To the best of our knowledge, this is the first paper to introduce and evaluate a midwife-led telephone clinic for the follow-up of patients who sustained $3 \mathrm{a}$ and $3 \mathrm{~b}$ OASI. As the midwife telephone consultation at 12 weeks postnatal is in part a triage service, with symptomatic patients offered a hospital appointment, the authors feel this is a promising service.

The response to the question from the telephone clinic: 'How well do you feel your options for a future pregnancy were discussed', was suboptimal with $63.2 \%$ answering very good/ good, $15.8 \%$ answering satisfactory, but $21.0 \%$ answering from neither good nor bad to very bad. Although the clinic is run by experienced midwives, this may be an area, they are less comfortable with, or capable of discussing and this will be explored further at a later date (outwith this paper).

We serve a large geographical area where travelling times can be up to 2 hours to reach our unit. We, therefore feel we can considerably reduce the burden for some patients with new babies, in terms of travel time, parking, and waiting time, by providing a telephone consultation.

One limitation to our study is the poor response rate to our postal survey with only $23.6 \%$ responding. A response rate of $56 \%$ can be achieved in postal surveys of postnatal women ${ }^{11}$. We did not send out reminders, which could have improved the re- sponse rate ${ }^{12}$ as our survey was anonymised. Other limitations include the retrospective design resulting in missing data, and the use of non-validated questions. In addition, the three midwives may counsel patients differently, but this reflects 'real life'.

The study, however, suggests that a midwife telephone clinic can be used as a triage service for symptomatic patients and as consultation for non-symptomatic patients. More robust data is required. Fundamental to this clinic set up is the option given to all patients to have a face-to-face consultant consultation.

\section{CONCLUSION}

A midwife-led telephone follow-up clinic for patients who sustained $3 \mathrm{a}$ and $3 \mathrm{~b}$ perineal tears at the time of vaginal delivery, seems to be an acceptable service for these patients with high satisfaction rate. We believe that a midwife-led telephone clinic has the potential to save time and resources for both patients and healthcare providers.

\section{REFERENCES}

1. Gurol-Urganci I, Cromwell DA, Edozien LC, Mahmood TA, Adams EJ, Richmond DH, et al. Third- and fourth-degree perineal tears among primiparous women in England between 2000 and 2012: time trends and risk factors. BJOG. 2013;120(12):1516-25.

2. Thiagamoorthy G, Johnson A, Thakar R, Sultan AH. National survey of perineal trauma and its subsequent management in the United Kingdom. Int Urogynecol J. 2014;25(12):1621-7.

3. Third- and Fourth-degree Perineal Tears, Management (Green-top Guideline No. 29) [Internet]. 2015. Available from: https://www. rcog.org.uk/globalassets/documents/guidelines/gtg-29.pdf.

4. Marsh F, Lynne R, Christine L, Alison W. Obstetric anal sphincter injury in the UK and its effect on bowel, bladder and sexual function. Eur J Obstet Gynecol Reprod Biol. 2011;154(2):223-7.

5. Ramalingam K, Monga AK. Outcomes and follow-up after obstetric anal sphincter injuries. Int Urogynecol J. 2013;24(9):1495-500.

6. Burch J. Enhanced recovery and nurse-led telephone follow-up post surgery. Br J Nurs. 2012;21(16):S24-6, S8-9.

7. Uppal S, Nadig S, Mielcarek MW, Smith L, Jose J, Coatesworth AP. Patient satisfaction with conventional and nurse-led telephone follow-up after nasal septal surgery. Int J Clin Pract. 2003;57(9):835-9.

8. Wootton R, Bahaadinbeigy K, Hailey D. Estimating travel reduction associated with the use of telemedicine by patients and healthcare professionals: proposal for quantitative synthesis in a systematic review. BMC Health Serv Res. 2011;11:185.

9. Jefferis H, Muriithi F, White B, Price N, Jackson S. Telephone follow-up after day case tension-free vaginal tape insertion. Int Urogynecol J. 2016;27(5):787-90.

10. Bateman AG, Neilens H, Gericke CA, George J, Freeman RM. Is there a need for postoperative follow-up after routine urogynaecological procedures? Patients will self-present if they have problems. Int Urogynecol J. 2014;25(3):381-6.

11. Sjetne IS, Iversen HH, Kjollesdal JG. A questionnaire to measure women's experiences with pregnancy, birth and postnatal care: instrument development and assessment following a national survey in Norway. BMC Pregnancy Childbirth. 2015; 15:182.

12. Asch DA, Jedrziewski MK, Christakis NA. Response rates to mail surveys published in medical journals. J Clin Epidemiol. 1997;50(10):1129-36.

\section{DISCLOSURE STATEMENTS}

There was no conflict of interest, informed patient consent was obtained, and the study was approved by the local ethical committee. The authors of the publication did not receive any financial support by any grant/research sponsor

Correspondence to:

Sami Shawer - Hardwick road - Stockton-on-Tees TS19 8PE

Stockton-on-Tees - United Kingdom

E-mail: sami.shawer@doctors.org.uk 